\title{
Platón en la caverna: una lectura peirceana del mito
}

\author{
Plato in the cave: A Peircean read of the myth \\ RAMON VILÀ VERNIS \\ Universitat Autònoma de Barcelona
}

Recibido: 01-10-2008 Aprobado definitivamente: 19-11-2008

RESUMEN

Es habitual señalar a Platón como uno de los portavoces del dualismo -el propio Platón era el primero en hacerlo-, a pesar de lo cual Peirce parece dispuesto a discutir esta idea, al menos por remisión a cómo sería la doctrina platónica si ciertas tendencias dentro de ella fueran debidamente reforzadas. El decorado escogido para poner en escena esta relectura, así como sus consecuencias para la adscripción de Platón como filósofo dogmático o científico (sic), es el mito de la caverna. Como ocurre tantas veces, la relectura trabaja en ambas direcciones y la ciencia tampoco sale indemne de sus tratos con la dialéctica.

PALABRAS CLAVE

PLATÓN, PEIRCE, MATEMÁTICAS, DIALÉCTICA, CIENCIA

\begin{abstract}
Plato is generally considered to be -first of all by himself- an advocate of dualism. Peirce seems ready to discuss this description though, at least on account of what his philosophy would be, if certain trends in it were duly reinforced. The myth of the cave is chosen here as the perfect set to stage this re-reading of Plato, and its consequences regarding his ascription as a dogmatic or -surprisingly enough- a scientific philosopher. As it usually happens, the re-reading works both ways and science is also touched by this pairing up with dialectics.
\end{abstract}

KEY WORDS

PLATO, PEIRCE, MATHEMATICS, DIALECTICS, SCIENCE

(C) Contrastes. Revista Internacional de Filosofía, vol. XIV (2009), pp. 241-255. ISSN: 1136-4076

Licenciatura de Filosofía, Universidad de Málaga, Facultad de Filosofía y Letras

Campus de Teatinos, E-29071 Málaga (España) 


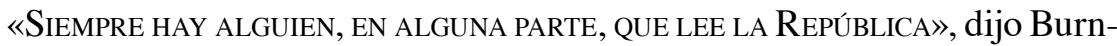
yeat (Burnyeat 1998), aunque podría haberlo dicho perfectamente de una parte de la obra tan sólo, el Libro VII, donde se expone el célebre mito de la caverna. Este mito es todo lo que conocen muchas personas sobre Platón, e incluso los especialistas le dedican mucho más tiempo y tinta que a ninguna otra parte de su obra. Es improbable sin embargo que este resultado hubiera satisfecho a su autor, quien denunciaba la poesía en ese mismo libro como una distracción peligrosa para el filósofo, y que sólo dejaba abierta la puerta a una literatura puramente pedagógica, inspirada y vigilada de cerca por la filosofía. Peirce por su parte le habría respondido que la culpa era toda suya, por hacer un uso demasiado liberal de su excepción: «No ha habido ningún filósofo en ninguna época que haya mezclado la poesía con la filosofía con tanta desfachatez como Platón» (Ess II, p. 38).

En opinión de Peirce, la costumbre platónica de mezclar poesía y filosofía, sentimiento y razón, forma parte de una tendencia más amplia de este filósofo a tomarse licencias que no debería, o dicho de forma más general, de una cierta tendencia suya a exagerar. Lo cual no es ningún defecto menor para Peirce, sino la fuente misma de todos los errores que cometió Platón personalmente, e incluso de los errores -más numerosos aún- que legó a la posteridad (CP 2.191). ${ }^{1}$ Este juicio crítico no le impide, sin embargo, mostrar una indulgencia especial hacia el célebre filósofo griego, pues descubre en él la notable peculiaridad de que los errores que comete son al mismo tiempo, aunque en otro sentido, grandes aciertos. Y como le concede el dudoso honor de haber cometido errores más graves que la mayoría de los filósofos, también le concede haber acertado mucho más que todos ellos; tanto es así que «por lo que se refiere a la concepción general de la importancia y el propósito último de la ciencia, ningún filósofo que haya vivido nunca los ha formulado más claramente que este temprano filósofo científico» (Ess II, 37).

La mera mención de Platón como un filósofo científico llamará seguramente la atención de muchos. Pero antes de entrar a decidir si merece este título, es importante ver en qué sentido puede decirse que Platón exagera en general, y qué relación puede guardar esa tendencia tan aparentemente excusable con sus errores, que no sólo incluyen el de mezclar poesía y razón, sino también, según la sucinta pero descorazonadora lista que ofrece Peirce, el de preferir lo discreto sobre lo continuo, lo actual sobre lo potencial y, como colofón de todo ello, el de atribuir un valor práctico a la ciencia (Ess II, 37-38). Dicho sentido es mucho más concreto de lo que cabría esperar por el uso habitual del término, pues para

1 Véase tb. 1.662, 2.148, 5.525, 6.445. De hecho, todas estas alusiones no hacen sino apuntar al hecho de que la exageración puede funcionar como equivalente del dualismo y del nominalismo -el término más frecuente en las condenas filosóficas de Peirce. 
Peirce la exageración es el vicio definitorio del dualismo, casi se podría decir que es aquello en que consiste el dualismo. No es extraño, pues, que el filósofo que se presentó a sí mismo como el «apóstol de la dualidad» (Ess II, 38) ocupe un lugar especial dentro de la historia de este vicio.

Hay pocos ejemplos filosóficos más adecuados que el mito de la caverna para ilustrar la estrecha relación que cabe establecer entre el dualismo y la exageración. La escenografía del mito es bien explícita: el centro del escenario está ocupado por un poderoso umbral que parte el espacio en dos y obliga a entender cada cosa que aparece de un lado en oposición a otra que se encuentra del otro lado: luz frente a oscuridad, exterior frente a interior, saber frente a ignorancia, virtud frente a vicio, libertad frente a sumisión, etc. Es más, la misma fenomenología básica se proyecta hacia todos los rincones del escenario, de tal modo que cada paso que se da en él se convierte en una nueva repetición del gesto fundamental de cruzar el umbral. Pero a pesar de dominar tan completamente el escenario dramático, el umbral es también aquello que no está presente propiamente en ningún lugar: todo se halla siempre de un lado o del otro, nunca en el umbral, hasta el punto de que éste no tiene mayor consistencia ni contenido que los propios términos que separa.

En el texto platónico, el umbral en cuestión se encarna con preferencia en la luz que debería esperarnos del otro lado. La luz «ofende los ojos» del prisionero y le impide «distinguir los objetos cuyas sombras veía antes», para convertirse luego en dolor cuando le obligan a mirarla directamente; cuando entra en la caverna otra vez, se le «llenan los ojos de tinieblas», dejándole literalmente discapacitado ante sus ex compañeros de la caverna - una vulnerabilidad que se revelará finalmente trágica, como sabemos (Rep 515c-e, 516e). Este tratamiento de la luz merecería seguramente el calificativo de «efectista» en la opinión de muchos críticos literarios, y lo mismo cabría decir de buena parte de los elementos que aporta Platón (las cadenas, la conspiración, el crimen final) al sencillo relato de formación que evoca para su público. Y lo cierto es que los comentaristas filosóficos también han mirado con ojo crítico este aspecto del relato: Annas por ejemplo encuentra que esos repentinos saltos de la sombra a la luz y de la luz a la sombra no casan bien con la visión más matizada del ascenso en el saber que sugieren un sinfín de otros pasajes platónicos, empezando por las dos imágenes que preceden al mito dentro de la propia República (el sol y la línea). Desde una perspectiva de conjunto, insiste Annas, el mito de la caverna se revela como un golpe de efecto puntual, un intento de sacudir la conciencia de su público a base de llevar la miseria de su situación presente hasta extremos risibles, y de ponerle a su vez la superación de todos esos males al alcance mismo de la mano (Annas 1981, pp. 252-256 ss).

Pero por muy edificante que fuera la finalidad del relato, es difícil no concluir el minucioso análisis de Annas sin pensar que la eliminación de la poesía 
del ámbito de la filosofía -aunque no de la república, naturalmente- debería ser mucho más completa de lo que parece pensar Platón. La exageración literaria se adivina como un virus mucho más pernicioso para el pensamiento que ninguna objeción explícita, por poderosa que ésta sea, pues mina el sentido de lo que se dice hasta poner en peligro la propia posibilidad de la argumentación racional. Para Popper, como sabemos, esta torpeza platónica toma más bien el aspecto de un cálculo interesado: la confusión de razonamiento y literatura es para él la esencia misma de la metafísica, y ésta a su vez un caballo de Troya que oculta siempre algún afán de dominación. ${ }^{2}$ Tal vez hoy nos costará suscribir una posición tan suspicaz, pero la idea de que la exageración metafísica tiene mucho que ver con nuestros problemas cotidianos sigue bien viva, y no únicamente en la tradición de Popper: así, Bruno Latour escoge precisamente la caverna platónica como decorado para una divertida parodia de los maniqueísmos que minan nuestra forma de entendernos a nosotros mismos y nuestra relación con el mundo (Latour 2004, p. 23 ss.). ${ }^{3}$

Ya hemos visto que Peirce compartía la repulsa por cualquier tipo de mezcla entre poesía y filosofía, y sin duda era el primero en avisar de los peligros de la falta de rigor y sobriedad teóricas. Sin embargo, no está tan claro que diera la culpa a la poesía de las exageraciones platónicas; es más, a juzgar por su definición de aquello en que consiste la bondad estética -una incursión teórica que él mismo reconoce algo alejada del terreno que le era más familiar-el mito de la caverna debería parecerle tan mala literatura como mala filosofía. ${ }^{4} \mathrm{La}$ proverbial tendencia platónica a la exageración tenía en su opinión un origen muy distinto, un origen a primera vista sorprendente, pues se sitúa en el centro mismo del territorio que todos ponen gran empeño en proteger de su contagio: el espejo del pensamiento racional, las matemáticas. Según esto, Platón estaba tan deslumbrado como el prisionero de su relato, y si iba dando tumbos era sólo porque estaba más cerca que nadie de la verdad. Pero no nos anticipemos.

En su historia de la filosofía, Russell insistía en la fascinación que debieron producir entre los griegos las primeras deducciones matemáticas, en la sensación de omnicomprensión que debía sentir quien las formulaba; según él, cabe considerar el nacimiento de la filosofía y la extraordinaria explosión de modelos teóricos a que dio lugar como una expresión directa de este estado de ánimo (Russell 2004, p. 38 ss.). También Platón da un papel destacado a las

2 El capítulo 9 de La sociedad abierta y sus enemigos conecta magníficamente la preferencia por lo «grande» con las premisas metafísicas, las tendencias autoritarias y el esteticismo.

3 Detrás de las inconsistencias se adivina también aquí el afán de dominación, por más que los opresores de su versión se parezcan mucho a los liberadores que tiene Popper en mente.

4 Véase CP 1.383, 5.291. 
matemáticas dentro de su mito de formación, un papel que se identifica en gran medida con la luz que señala el umbral de la caverna y revela cada cosa que hay sobre el escenario como lo que es realmente. ${ }^{5}$ La metáfora no anda aquí nada lejos del sentido literal: según explica Platón, las matemáticas nos enseñan a ver los objetos de un modo enteramente distinto a como estamos acostumbrados a verlos, de un modo que rompe con lo que considerábamos más cierto de ellos. Al considerar algo matemáticamente, usamos su realidad visible, tangible etc., como una mera sugerencia a partir de la cual definir un objeto puramente con el pensamiento. Ahora bien, de este objeto así definido podemos decir que poseemos un conocimiento absoluto, perfecto, o al menos incomparable a nada que podamos conocer de otro modo: podemos recorrer todas las relaciones que existen entre los diferentes rasgos que hemos atribuido al objeto hasta que no quede nada que escape a nuestro conocimiento, ni nos suscite la duda más pasajera. En palabras de Peirce, acerca de este objeto somos «virtualmente omniscientes; es decir, sólo la falta de tiempo, de perseverancia o de actividad mental puede evitar que realicemos los experimentos requeridos para comprobar de forma positiva si una combinación dada ocurre o no» (CP 3.527).

No parece que la iluminación matemática tenga nada que envidiar a cualquier otra revelación histórica o religiosa que haya podido disfrutar la especie humana. Desde este punto de vista, la exageración platónica no parece tanto un condimento para el consumo popular -o una estratagema para la manipulación política- como un intento de dar la auténtica medida de lo que se está diciendo. La diferencia entre la comprensión usual un objeto y la comprensión que permiten las matemáticas es prácticamente inconmensurable, un salto instantáneo de la nada al todo en el más literal de los sentidos. En este punto podríamos estar tentados de leer el conjunto de los diálogos platónicos a la luz del mito de la caverna, en lugar de hacerlo al revés, y concluir que la palabra «diálogo» está usada con cierta doblez irónica. No sólo deberíamos verlos como caminos abiertos hacia el saber, sino también como muros de palabras que hacen tangible la distancia que nos separa actualmente de él -a fin de cuentas, eran los primeros folletos de promoción universitaria. La brecha que separa al maestro dialéctico de sus interlocutores convierte el intercambio la mayoría de las veces en un diálogo de besugos, tanto por la parte iluminada como por la no iluminada, pues ninguno ve realmente lo que ve el otro en lo que se está diciendo. En la propia República, por poner un ejemplo, Sócrates

5 La imagen de la línea convierte las matemáticas y disciplinas afines en el primero de los dos segmentos que constituyen el mundo de lo inteligible; el segundo corresponde a la dialéctica. La correlación exacta de estas indicaciones con el universo metafórico del mito de la caverna vale para una discusión tan larga como se quiera, pero en todo caso es claro que el primer contacto con la luz es de naturaleza matemática, y matemático también es todo el proceso inicial de superación del deslumbramiento a través de sombras y reflejos. 
apenas logra fingir algún interés hacia la posición de Trasímaco, por más que todo su argumento se construye -al menos a ojos de sus oyentes y lectores- en respuesta a una objeción suya.

Pero si la revelación matemática parece ofrecer un atisbo de otro mundo, también pone la fe del neófito inmediatamente a prueba, pues no le permite avanzar ni un solo paso hacia el nuevo horizonte que le acaba de mostrar -un rasgo nada infrecuente entre las revelaciones. Como hemos visto, el matemático sólo logra alcanzar esa perspectiva privilegiada sobre su objeto en la medida en que lo define él mismo previamente, lo cual le convierte en un auténtico supermán teórico, capaz de recorrer al instante las distancias más inmensas, doblar y someter sin resistencia cualquier cosa que se encuentre en el mundo recién creado, y anticipar con certeza el resultado de todas sus acciones; puede incluso cumplir el sueño infantil de comerse la tarta y conservarla al mismo tiempo, si tal es su deseo, pues dispone del poder prácticamente divino de ampliar o reducir su definición a voluntad, de tal modo que «dos proposiciones contradictorias entre sí puedan darse por separado» (CP 3.527). Pero en último término debe reconocerse que las matemáticas no se interesan por la realidad, o lo que es lo mismo, por «cómo son las cosas de hecho, sino [por] cómo podría suponerse que fueran, si no en nuestro universo, tal vez en algún otro» (CP 5.40). Las palabras son de Peirce, pero podrían ser perfectamente de Platón, quien denunció el conocimiento que nos ofrece las matemáticas literalmente como «un sueño».

Sin embargo, Platón cree haber visto lo suficiente en este sueño como para adivinar el camino que le permitirá salir del círculo de la definición y dar en la realidad propiamente dicha: se trata de extender la indagación a todos los objetos definibles y recorrerlos con la ayuda de otros pensadores hasta determinar las relaciones que se dan entre todos ellos y remontarse -invirtiendo en cierto modo el razonamiento matemático-hasta sus primeros principios. Se trata, en fin, de llegar a definir el modelo de modelos, el modelo de todo lo definible. Alcanzado este punto, el pensador no se halla ya limitado propiamente por ninguna definición, y por lo tanto debería tener los pies firmemente instalados sobre la realidad, una realidad de la que poseería además un conocimiento total, esta vez sí digno de un dios.

Se ha hablado mucho de la escasa claridad y concreción de la noción platónica de dialéctica, la ciencia encargada de sacarnos del sueño matemático. Annas se hace eco de la célebre definición de Robinson, según la cual la dialéctica no significa más que «el método ideal, sea lo que sea eso». ${ }^{6} \mathrm{Y}$ en efecto,

6 La cita prosigue: «In so far as it was thus merely an honorific title, Plato applied it at every stage of his life to whatever seemed to him at the moment the most hopeful procedure» (Robinson, Plato's Earlier Dialectic, citado en Annas 1981, p. 276). Desde la moderna perspectiva de Robinson, es la especialización del método lo que le confiere alguna autoridad; todo indica que para Platón era exactamente al revés. Lo mismo cabe decir de Peirce. 
tal vez tengamos ahí la definición más exacta posible: a juzgar por las escasas indicaciones que ofrece Platón, el método dialéctico consiste en responder a todas las preguntas relevantes y superar todas las objeciones pertinentes. ${ }^{7}$ Sólo esa clase de totalidad -en último término imposible de delimitar, y por lo tanto de definir- puede convertir el sueño del matemático en la vigilia del sabio, o dicho de otro modo, sólo ella puede conferir alguna verdad a las conclusiones de la investigación dialéctica; el camino que lleva a la realidad es por definición el más largo, y antes del final no puede haber ningún conocimiento propiamente dicho. En este sentido, Platón estaría probablemente de acuerdo con sus intérpretes modernos en que sus imágenes engañan tanto como iluminan, pero a diferencia de éstos no creería que proceder únicamente a base de argumentos supone una gran mejora, pues en la medida en que éstos sigan siendo parciales tampoco podrán hacer más que sugerir o indicar el camino de la verdad; en cierto modo, los argumentos pueden resultar incluso más engañosos que los mitos, pues nos invitan a darlos por verdaderos en sí mismos y a detener así prematuramente el recorrido dialéctico. ${ }^{8}$ De ahí también lo malos que son algunos de los argumentos platónicos, tal como insisten -a veces con cierto exceso de celo- un buen número de comentaristas recientes: ni siquiera puede decirse que sean algo más que un esbozo, pues el dialéctico sólo ve en ellos un lugar de paso, en sí mismo insignificante y carente de verdad.

De acuerdo con los términos del mito platónico, la iluminación matemática nos enseña a ver nuestra experiencia ordinaria como una caverna; y tal como se ha reconocido siempre sin dificultad, la caverna es una metáfora de la particularidad, entendida muy intuitivamente como una prisión, un lugar cerrado, sin duda también estrecho y bajo. Quien se encuentra encerrado tras esos muros casi infranqueables, el provincianismo mismo e inevitable del fragmento de lo real donde le ha tocado vivir, no tiene acceso más que a éste o a aquél «dato» particular; la palabra recoge bien su posición dependiente: en la medida en que está en el mundo de lo particular, las cosas le son muy literalmente dadas. Dadas por la sociedad, por la enseñanza, por la política, pero más generalmente por la limitación y la finitud misma de su experiencia -tales son los temibles carceleros de Platón. Pero si éste es el sentido que debemos darle a la caverna, entonces la salida no puede consistir en acceder a ningún lugar distinto de la caverna misma -y en esto debe reconocerse que la metáfora platónica resulta mucho menos que intuitiva- pues en la medida en que ésta quedara excluida nos encontraríamos de nuevo encerrados en un afuera aparente, escuchando a

7 Rep 510bss, 532d-535a (en especial 534b-e); véase tb. Fedr 276e-277c.

8 «To be sure, the dialectic exploration of reality, which is achieved in argumentational logos, is the ultimate aim of the philosopher» (Szlezak 1999, p. 98), aunque el movimiento argumentativo encuentra un apoyo esencial en el mito para orientarse y perseverar en su recorrido. 
pájaros de trapo y reflejándonos en ríos de mentira. El asunto podría quedarse en un simple fiasco poético, si no fuera porque en una forma $u$ otra se repite por toda la obra de Platón, hasta el punto de convertirse en todo un topos teórico: el problema de los «grados de la realidad». Muy previsiblemente, este es también el punto donde surge el diferendo fundamental entre Peirce y Platón. Tal vez sorprendan más los términos en los que se formula el diferendo, unos términos que parecen más propios de una pelea de bar que de un debate filosófico: a todo aquél que piense que la realidad es el «destilado puro de la Razón», Peirce le desea que vaya alguien a distraerle de sus especulaciones con un buen bastonazo en la espalda... a ver si así se da cuenta de que todavía le falta algún dato para completar su modelo ideal (CP 5.92). ${ }^{9}$ Sin embargo, la violencia del argumento peirceano tiene más de irritación que de verdadero enfrentamiento, pues no le exige a Platón sino que lleve hasta sus últimas consecuencias sus propios principios, es decir, que no limite la investigación dialéctica al terreno confortable y fácilmente accesible de las ideas de los hombres. En definitiva, de lo que acusa a Platón es de haber caído, él también, en la tentación cavernícola de aferrarse a lo familiar y de dar por más real lo que simplemente tiene más cerca -en este caso, su propio pensamiento y el de sus contertulios habituales.

En su célebre artículo de 1878 sobre La fijación de la creencia, Peirce había dejado claro que el método dogmático - del que Platón es en cierto modo uno de los primeros y más notorios representantes-debía llevar necesariamente al método experimental; sólo la aplicación parcial e inconsecuente de sus propios principios «dialécticos» lo impedían. Pero ¿por qué cae Platón en este error? Tal como deja bien claro Peirce en su artículo, la razón por la que un hombre no investiga más una cuestión es siempre y en todo lugar la misma: que no hace falta -o al menos así se lo parece a él. De hecho, también Platón trata más o menos de perezosos a los astrónomos que estudian los movimientos de los astros dirigiendo sus ojos hacia el cielo en lugar de hacerlo hacia una hoja de papel, pues entiende que se limitan a observar los movimientos de tal o cual roca que se encuentran frente a las narices al levantar la vista, en lugar de estudiar todas las relaciones posibles entre los cuerpos en movimiento, así como las leyes que rigen sus ciclos y sus combinaciones; en este sentido dice Platón, con mucha razón, que nada se aprende realmente practicando la astronomía de este modo. ${ }^{10}$ Pero si alguien le respondiera, tal como haría sin duda Peirce, que el astrónomo que mira hacia el cielo deberá seguir mirando hasta que se le sequen los ojos,

9 La referencia explícita es a Hegel, pero es perfectamente extensible a Platón en su calidad de dogmático. Es más, es un lugar común en historia de la filosofía que Hegel encontró su modelo filosófico en Platón, y más particularmente en su ejercicio dialéctico más puro, el Parménides.

10 Rep 529-530c. Al final del pasaje se asegura que la concepción platónica de la astronomía convierte esta ciencia en mucho más difícil de cómo se practica en la actualidad. 
y comparar los resultados de su abnegada contemplación con los de un número ilimitado de otros observadores apostados en un número también ilimitado de puntos de observación, hasta completar un cuadro integral de los movimientos de los astros tanto en el espacio como en el tiempo, Platón concedería ciertamente que tal comunidad ilimitada de astrónomos -en el supuesto de que fuera posible- debería aprender exactamente lo mismo que su pequeña compañía doblada sobre la hoja de papel. Su objeción quedaría reducida a que no hace falta llegar a tales extremos.

El pasaje de la República donde se aconseja practicar la astronomía sin levantar la vista hacia el cielo se ha convertido en un lugar común de asombro y perplejidad filosófica, y hay quien duda incluso de que Platón pudiera estar hablando en serio. Pero la radicalidad de la respuesta peirceana hará levantar también probablemente más de una ceja. Sin duda, es muy razonable sugerir que no hace falta recorrer uno por uno todos los casos individuales dentro del dominio de una ciencia para llegar a algún conocimiento; más aún, tal recorrido no enseña absolutamente nada si no va acompañado de una contemplación simultánea del conjunto -en eso consiste justamente conocer algo, o concebir una idea. Luego si para aprender es preciso contemplar las cosas en conjunto y no una por una -o lo que en la imaginería platónica sería más bien cambiar los ojos sensibles por los ojos de la razón- ¿por qué no hacerlo desde el principio en lugar de esperar al final? ¿O tal vez desde algún punto a medio camino? En esencia, el motivo que ofrece Peirce es que no podemos estar tan seguros como creía Platón de aquello que vemos cuando contemplamos las cosas «en conjunto»: «Sería un gran error suponer que en la experimentación ideal no existe ningún riesgo de error; [aunque] el rigor y la dedicación permiten reducir indefinidamente tal riesgo» (CP 3.528). ${ }^{11}$

Ni siquiera en la soleada región de las matemáticas puede uno estar seguro de ver bien y de no necesitar una segunda ojeada. No deberíamos dejarnos engañar por las facilidades que encontramos en este terreno, y suponer que nos hemos liberado de una vez por todas de las limitaciones de nuestro conocimiento, tan patentes en cualquier otro dominio; $y$ tenemos buenas razones para desconfiar, pues si vamos al fondo el matemático no hace nada distinto -aunque lo haga de modo más libre y controlado- de lo que hace el habitante del rincón más oscuro de la caverna. Por seguir con la metáfora ocular: sólo podemos contemplar varias cosas al mismo tiempo al precio de reducir en alguna medida lo que vemos de cada una -o si se quiere, al precio de sustituirlas por un modelo definido por nosotros mismos. Esto vale tanto para los ojos que tenemos en el rostro como para cualquier duplicación suya que podamos proyectar a otro nivel cognitivo. (En una formulación más próxima a Peirce, conocer algo es conocer algo «como

11 Véase tb. CP 7.186; 1. 130; 3.529. 
algo»). El ejemplo extremo de las matemáticas sólo ha servido pues para que nos demos cuenta de la verdadera naturaleza del problema que arrastra toda forma de cognición, desde la más rudimentaria y vulgar hasta la más sofisticada y formal: no hay modo de escapar del modelo para dar en lo realmente real. Y así entendido el problema, no parece que la estrategia platónica de reservar nuestra mirada para las grandes vistas pueda sernos de gran ayuda; más bien diríamos que sólo servirá para encerrarnos aún más en nuestra prisión, la cual, por entregarme yo también a la licencia metafórica, cada vez se parece menos a la angosta caverna de lo particular y más a la casa de muñecas de lo general. Pero no es la intención de Peirce invertir simplemente la formulación de Platón y revelarnos encerrados en lo general -en el «signo», como es moda decir-cuando éste nos creía encerrados en lo particular; más bien se trata de poner en cuestión cualquier exagerada oposición entre lo particular y lo general en el terreno del conocimiento. Lo absolutamente particular es tan inaccesible para nosotros como lo absolutamente general, o mejor dicho ambos son -en un sentido que más adelante quedará claro- distintos nombres para la misma «realidad real».

Sin embargo, y por más que la metodología astronómica de Platón le convierta en un extraño invitado entre los precursores de esta ciencia, Peirce entiende que su intuición fundamental sigue siendo correcta, e incluso va más lejos que muchos de los que se han llamado defensores del método experimental. Justo antes de que se levante el telón frente a la gran escenografía del mito, Platón ofrece una explicación muy esclarecedora acerca de la manera cómo hay que interpretarlo, una indicación en la que se encuentra ya implícito todo lo que Peirce podría querer marcar en rojo en sus diálogos. Platón ofrece una única clave para distinguir el método de la matemática -junto con todo método inferior de conocimiento- del método propio de la dialéctica: que unos confían en lo que se halla al principio de la investigación, mientras que el otro confía únicamente en lo que se halla al final. Esa es toda la precisión que parece capaz de alcanzar Platón en el terreno de las explicaciones, antes de regresar al brumoso mundo de los mitos; y debe decirse que Peirce tampoco tendría mucho que cambiar o que añadir a esa explicación. Lo que sí diría probablemente es que la metáfora espacial de la caverna complica y traiciona en gran medida la idea que se trata de formular. Pues si lo que importa no son las coordenadas del punto de partida y de llegada -dentro o fuera, arriba o abajo... - sino la forma como debe entenderse el recorrido - si «venimos de» o si «vamos hacia»- ¿por qué no quedarnos con una sencilla imagen temporal, y decir que el conocimiento debe confiar no en lo que tiene antes sino en lo que tiene después, no en el primer principio sino en la opinión final? ${ }^{12}$

12 La primera y más clásica formulación peirceana del dilema de la realidad se encuentra en su recensión de Berkeley, Ess I, p. 91. 
La idea de encomendarse al futuro y no al pasado, a lo que se va a conocer y no a lo que ya se ha conocido, tiene un objetivo muy claro: el mismo que perseguía Hernán Cortés cuando ordenó a sus hombres quemar las naves detrás suyo. La exigencia de cortar con el pasado incluye en general cualquier garantía, apoyo o «fundamento» en los que pudiera confiar el investigador, pues la seguridad que obtiene así no es otra que la irónica seguridad de los barrotes de su jaula. No hay nada que pueda «sacarnos» de una experiencia limitada a éste o aquél dato... como no sea el siguiente dato, y el siguiente, y así sucesivamente. Y éste es un movimiento que no puede dejar de empujarnos fuera del círculo de los problemas formales y de las opiniones humanas, y llevarnos en pos del siguiente dato hasta los senderos más pedregosos de la investigación, los más incómodos y resistentes al escrutinio del investigador. Peirce no pretende otra cosa con su bastonazo que darle ánimos a Platón para que recorra también esta parte del trecho; pues la única vía de salida de la caverna de lo particular-por quedarnos con la formulación más cara a Platón- consiste en recorrer hasta el final las relaciones de cada particular con todos los demás particulares. Platón habla a veces como si el dialéctico debiera alejarse de algún modo de lo particular, cuando en realidad y de acuerdo con su propia descripción de la dialéctica, de lo que se trata es más bien de ir al encuentro de lo particular, de exponerse a ello tanto como sea posible. Así lo hace Platón -vía Sócrates- al exponerse casi obsesivamente a las objeciones y a las preguntas de sus interlocutores, y así propone Peirce que siga haciéndolo al exponerse a la objeción que constituyen en sí mismos y por definición todos los demás particulares, estén o no matriculados en la Academia.

Entre las pruebas de cargo presentadas contra la dialéctica platónica figura con frecuencia su carácter contradictorio: por un lado se habla de ella como de un proceso colectivo de diálogo y análisis, y por el otro -sobre todo hacia los estadios finales del progreso en el conocimiento- parece tratarse de un acceso intuitivo e inmediato, una «visión» esencialmente privada de la verdad (Annas 1981, pp. 282-283). Pero en el contexto donde Platón habla de tales visiones, «ver» debe leerse como una metáfora de comprender; ciertamente una metáfora poco afortunada, pues difícilmente la idea de una visión nos incitará a imaginar un análisis integral que no sólo exige un diálogo de amplitud ilimitada, sino también una exploración ilimitada de lo real en todos sus pormenores. Pero más allá del acierto de las imágenes platónicas, no parece que haya ninguna contradicción en su noción de dialéctica, ni tampoco ninguna mística. Al menos, no tiene por qué haberlas si decidimos entender, con Peirce, que su método no es otro que el método científico -y que su «inversión» dialéctica de la deducción no es otra cosa, como cualquiera después de Aristóteles habría protestado, que la inducción. No es muy probable, sin embargo, que una lectura como ésta resulte demasiado convincente para un platonista, el cual pensará sin duda que 
Peirce se limita a proyectar sobre Platón las nociones científicas al uso. Pero en justicia debería decirse que se trata también, al menos en la misma medida, de lo contrario: el método experimental según lo concibe Peirce -y su concepción difiere más de lo que parece de las nociones al uso- es la dialéctica misma de Platón, sólo que llevada hasta sus últimas consecuencias.

De acuerdo pues con lo dicho anteriormente sobre la dialéctica, y contra lo que pudiera pensarse al consultar el índice de los Collected Papers, para Peirce apenas hay nada que decir sobre el método experimental -y buena parte de lo que se dice lleva más a engaño que otra cosa. También la ciencia es «el método ideal, sea lo que sea eso». En concreto, cualquier certeza o seguridad que pretenda extraer el científico de los instrumentos, los procedimientos o los peculiares objetos de su investigación no hace más que desvirtuar el sentido de lo que hace. Platón escogió maravillosamente bien la imagen de la caverna para indicar que la prisión del investigador es la idea misma de seguridad; y pésimamente mal, al mismo tiempo, pues con ello parece sugerir que lo real es algo que está en otra parte -o hecho de otra sustancia, o... - con lo que convierte la salida prometida en una nueva y desesperante puerta de entrada. Si no ha de decir más cosas de las que «realmente» quiere decir, la imagen espacial de Platón debe reformularse en términos puramente temporales, y lo mismo cabe decir de los célebres «grados de la realidad» de los que aquel mito parecía ser el mapa. «Correctamente analizada», según Peirce, la filosofía de Platón no es diádica sino triádica, y los grados que distingue dentro de la realidad deben entenderse como la potencia, el acto y el fin.

El análisis que ofrece Peirce para probar una afirmación tan contraria a la letra de los textos platónicos no puede ser más escueto y alusivo. En particular, arranca de un punto aparentemente contrario a sus intereses: de la conocida crítica de Aristóteles según la cual Platón ignora las causas externas (eficiente y final) dentro de su cuadro de las causas. A lo cual responde Peirce con un característico juego de razonamientos truncados, más parecido a lo que la literatura conocería poco después como el «flujo de conciencia»; reconstruido, vendría a ser algo así como: Aristóteles no tiene razón cuando dice que Platón rechaza las causas externas, pues éste no rechaza realmente la causa final, aunque la tesis aristotélica se ve rescatada más allá incluso de lo que el propio Aristóteles pudo suponer por el hecho de que Platón sí rechaza la segunda de las causas internas, lo que apunta más bien a que no es Platón el dualista sino más bien Aristóteles -como lo demuestra que su esquema de las causas sea un puro juego de dualidades (Ess II, pp. 37-38). Ambos filósofos dicen pues lo que no piensan y piensan lo que no dicen, y la objeción dirigida contra Platón apunta ahora hacia Aristóteles.

¿Pero de dónde saca Peirce que Platón entienda mejor que Aristóteles -aun sin llegar a formularlo nunca- lo que éste describió como la causa final? Pues 
bien, de un lugar que a primera vista podría parecer también muy poco adecuado: la identificación de las ideas con números en la que Platón desembocó en su obra tardía. En efecto, podría parecer que el anciano Platón, agotado ya de su mal concebido esfuerzo por romper el círculo de las definiciones y salir finalmente a lo real, habría terminado por encoger el espacio propio de la dialéctica hasta hacerlo coincidir de nuevo con el dominio de lo que él mismo había definido en sus mejores años como un mero «sueño». Pero inmediatamente queda claro que Peirce ha optado por no leer así este giro final de la doctrina platónica: la peligrosa tesis de que «las ideas son los números», de acuerdo con la expresión que emplea Aristóteles para resumirla, ${ }^{13}$ va acompañada según Peirce de un reconocimiento progresivo de la íntima relación que guardan las ideas entre sí. Aunque sesgado, el movimiento dialéctico de Platón le ha ido apartando de su preferencia inicial por lo discreto hasta reconocer las ideas como una red de relaciones -en fin, como un continuo. El razonamiento, tal como reconoce el propio Peirce, quizás no esté completo, pero sí lo suficientemente esbozado como para concluir que Platón no ha tomado -aun cuando tal vez lo hiciera alguna vez-el objeto de las matemáticas por el suyo propio, sino que entiende más bien su objeto legítimo a imagen de como las matemáticas conciben el suyo.

Desde esta perspectiva, Platón no cree que los números nos ofrezcan la única realidad real, ni una realidad más real, ni siquiera -propiamente hablando- una realidad distinta de la que conocemos generalmente por la experiencia. Lo que los números nos ofrecen es una ventana incomparable para comprender en qué podría consistir comprender realmente un objeto. Nada más que esto estaría diciendo Platón al sugerir que la realidad última, la realidad verdaderamente conocida, deberá tomar la forma de un número. ¿Pues qué es un número, y qué lo distingue de las cosas «sensibles»? Un número no es nada más en sí mismo que sus relaciones con los demás números. No hay ningún «algo» opaco e ininteligible que sea el número y que quepa relacionar luego con otros «algos» opacos e ininteligibles que sean los demás números. El cinco es dos más tres, y uno más cuatro, y...: no es más lo uno que lo otro, ni tampoco es nada aparte o más allá de tales relaciones. Lo que estaría diciendo Platón es que la pesada sustancialidad de la cosa no es más que un efecto «óptico» derivado de la limitación de nuestra perspectiva, de nuestra incapacidad de recorrer exhaustivamente las relaciones de la cosa con la totalidad que la rodea. Si lo hiciéramos, la cosa terminaría por disolverse ante nuestros ojos en una matriz de relaciones: en ese momento, y no antes, podríamos decir realmente que hemos salido de la caverna.

Decir que la cosa es número es la forma más aproximada que tenemos de decir que lo real es en sí mismo relación; casi podría decirse que las paredes verdaderas de la caverna son los límites mismos de las cosas, los cuales no tie-

13 Met I, vi (p. 32 edición Austral). 
nen mayor contenido ni mayor realidad -como también Spinoza entendió- que nuestra propia ignorancia. También en este sentido puede decirse que no se conoce nada hasta que se conoce todo, y tal como anunciábamos antes, que lo particular coincide finalmente con lo general. ${ }^{14}$ Por eso concluye Peirce, contra todo lo que Platón sostuvo de palabra y por escrito, que la filosofía platónica no es en realidad diádica sino triádica: decir que lo real está constituido en último término por el uno y el dos vendría a ser como decir, en un lenguaje numérico, que la realidad precisamente no es número -según se desprende del análisis peirceano del «concepto» propio aquellos números. Y eso sin duda no es lo que habría dicho Platón, si hubiera sabido lo que estaba diciendo.

Tal vez algunos se sentirán incómodos ante esta manera de especular sobre lo que habría dicho o dejado de decir Platón en caso de que hubiera pensado algo distinto de lo que efectivamente pensó. Pero también se les podría hacer notar que el desinterés que manifiesta Peirce por la particularidad de lo que dijo Platón está en perfecta sintonía con el desinterés que manifiesta el propio Platón por este aspecto de sus doctrinas. El espíritu radicalmente sistemático con el que tanto Peirce como Platón abordan la tarea dialéctica -lo único que, en opinión de ambos, puede protegernos realmente del dogmatismo- se traduce en ambos autores en una desesperante tendencia a la revisión y al cuestionamiento de sus doctrinas pasadas, así como a esa otra forma implícita de revisión que consiste en la variación constante de términos y formulaciones.

Al hilo de lo anterior, es interesante observar que en 1910 Peirce todavía estaba de humor para añadir una frase a su artículo 1878 (CP 5.383). Al final de su exposición acerca del método dogmático, Peirce matizaba la visión casi enteramente negativa que había dado sobre él observando que a pesar de todo «este método es mucho más intelectual y respetable desde el punto de vista de la razón que ninguno de los que hemos tratado antes». Treinta años después, añadió: «Es más, en la medida en que no pueda aplicarse ningún método mejor, debería aplicarse éste, pues constituye la expresión del instinto, el cual debe ser la causa última de la creencia en todas las circunstancias». Con estas palabras, Peirce entregaba al método dogmático el gobierno de nuestras vidas en todos sus aspectos prácticos, pues es obvio que no se va a encontrar ningún «método mejor» -siendo la ciencia, o la dialéctica bien entendida, el único método mejor en catálogo-para lidiar con ellos. Considérese tan sólo que una forma razonable de definir lo que es una cuestión práctica sería decir que es aquélla que por su

14 En la «opinión final» deberán coincidir por definición lo general con lo particular, el signo con su objeto, o bien, por formularlo en los términos más generales, la primeridad con la segundidad. Lo cual deja bien claro que no se trata de ninguna «opinión» en ningún sentido usual del término; en cierto modo, y tal como ya observé en otro lugar, a lo que más se parece es a lo que Heidegger definió como la muerte, aunque una observación así suscita trampas y engaños casi tan grandes como los que permite evitar. 
propia naturaleza no puede esperar hasta el final del recorrido dialéctico -o lo que viene a ser lo mismo, hasta el fin de los tiempos- para ser resuelta. La definición deja inmediatamente claro por qué la idea griega y más particularmente platónica de que la ciencia pueda tener alguna relevancia práctica sonaba inmediatamente absurda para Peirce. ${ }^{15}$

\section{REFERENCIAS BIBLIOGRÁFICAS:}

ANNAS, J. 1981: An Introduction to Plato's Republic. New York: Oxford University Press.

BURNYEAT, M. F. 1998: «Plato as Educator of 19th-century Britain», Philosophers on Education, ed. Amélie Oskenberg Rorty. London: Routledge.

LATOUR, B. 2004: Politiques de la nature. Paris: La Découverte.

PEIRCE, C. S. 1931-1935, 1960: Collected Papers, vol. I-VI, ed. Charles Hartshorne y Paul Weiss. Cambridge: Harvard University Press. (1958) vol. VII-VIII, ed. Arthur W. Burks, Cambridge: Harvard University Press. (Citado como CP).

PEIRCE, C. S. 1998: The Essential Peirce, vols. I-II, ed. the Peirce Edition Project. Bloomington: Indiana Univesity Press. (Citado como Ess I o Ess II)

POPPER, K. 2006: The Open Society and its Enemies. London: Routledge.

RUSSELL, B. 2004: History of Western Philosophy. London: Routledge.

SZLEZAK, T. A. 1999: Reading Plato. New York: Routledge.

RAMON VILÀ VeRnIS, Universitat Autònoma de Barcelona.

Publicaciones recientes:

«La filosofía del futuro: el papel de las categorías peirceanas en el pensamiento pragmático», en Teorema XXVII/1 (2008), pp. 85-96.

\section{Línea de investigación:}

Ha presentado un trabajo de investigación titulado «La tabla del tres: las categorías peirceanas» (directora: Victoria Camps), y prepara actualmente su tesis doctoral sobre la lógica peirceana y sus implicaciones para el pragmatismo.

Dirección postal:

Pg. Sant Joan 199, 3-1, 08037, Barcelona, España.

Dirección electrónica: ramon_vila@yahoo.com

15 La alusión a que la creencia debe guiarse siempre por el instinto se explica a su vez por la definición peirceana de la creencia, que la ata irremisiblemente a la acción. Desde esta perspectiva, resulta obvio también que la creencia no tiene ningún lugar en la ciencia, ni al revés. 